\title{
Finite Impulse Response Filters for Stagger-Period Signals, their Designs and Applications
}

\author{
Xubao Zhang
}

\begin{abstract}
Those theories of conventional filters for the uniform-period signals do not apply to analysis and design of the finite impulse response (FIR) filters for the stagger-period signals. In this paper, we defined the fundamental concepts related to the stagger-period signals, derived the calculating equations, and described the time-variant property of the stagger-period filter; we proposed the Fourier transform pair between the frequency and impulse responses of this type filter, and proved the inverse of each other. Then, we discussed the design methods of stagger-period frequency-selective FIR filters, including lowpass, bandpass, and high-pass, presented the staggered windowing philosophies, illustrated different windows' effectiveness, and described the principles and designs of the optimized stagger-period high-pass filters with a match algorithm. As applications, we introduced three staggered optimization algorithms: eigenvalue, match, and linear prediction; and discussed performances of the filters designed for a moving target indication (MTI) radar. The stagger-period MTI filters not only extend the blind speed of flying targets, but also give an optimized improvement factor. Finally, we proposed a mathematical programming to search the best period code, which makes this type filter's velocity response flattened. Meanwhile, we compared properties of the stagger-period to uniform-period filters, and provided with some examples to illustrate the theories and designs.
\end{abstract}

Index Terms - stagger-period signal, time-variant filter, staggered FIR filter design, optimized MTI filter, velocity response

\section{INTRODUCTION}

As everyone knows, those theories and applications of the uniform-period signal processing have been available for the areas of electronics, communication, and radar etc. for several centuries [1]-[3]. However, these theories and processing of the stagger-period signal are studied and developed not for long time though users have also gained benefits from their applications; the benefits are impossible to rely on the uniform-period signal processing. In surveillance radar, the aircraft returns are desired signals, and the returns from terrain, sea, and weather etc. are undesired clutters. Such radar signal processing and data acquiring always cause a range-velocity ambiguity problem when uniform-period finite impulse response (FIR) filters are used. References [4], [5] early proved that the optimized stagger-period moving target indication (MTI) filter is a solution of eigenvalue problem of covariance matrix of the interference plus thermal noise, particularly, the MTI filter coefficients are the eigenvector corresponding to the least eigenvalue. They also examined that the resulting improvement factors (IFs) were

Published on January 8, 2021

Xubao Zhang, Xi' an Electronic Science and Technology University in

China; Unitron Hearing in Canada, Oticon Canada and Beltone Canada. equal to those from the uniform-period MTI filter under the same algorithm. Reference [6] introduced the blind speed problem in a unform-period MTI radar, including the causes and solutions to eliminate it. Generally, the most effective and low-cost approach to eliminate blind speed is to utilize stagger-period FIR filters. Reference [7] presented three algorithms for the MTI filter design, including least squares, convex optimization, and min-max design; these design technologies enabled the MTI filters to maximally suppress the clutters and enhance the target signals. However, their experimental data showed that resulting IFs were not maximized yet. Reference [8] pointed out a similar issue in a weather radar, and proposed their strategy and implementation, utilizing multi-pulse repeat frequency (PRF) technology: different pulse batches were of stagger periods, but the uniform-period filters were used to process the uniform-period batch returns. This could effectively remove the false alarm of a strong thunderstorm from a long distance.

Reference [9] presented the Dirichlet transform pair of nonuniformly sampling signals, but he did not give a proof of the inverse of each other. This was an early study on the stagger-period signal processing theory. Reference [10] described some concepts, definitions, and properties of the stagger-period sequences, and proposed two staggered Fourier transform pairs: one between a stagger-period sequence and its spectrum, and the other one between a stagger-period auto-correlation sequence and its power spectrum density; he also proved the inverses of each other of the two transform pairs. Based on [3], [6], and [10], this paper studied the essential theories of stagger-period FIR filters, indicated their properties by comparing to the uniform-period FIR filters, and illustrated designs and applications of these type filters.

\section{FUNDAMENTS OF STAGGER-PERIOD FIR FILTERS}

\section{A. Concepts of a stagger-period FIR filter}

In reality, there exists a sort of discrete-time signals, whose sampling periods are unequal or stagger, thus, they are not sorted into the conventional discrete-time uniformperiod signals. Given a discrete-time signal $x\left(t_{n}\right), n \in\{0, \pm 1$, $\pm 2, \cdots\}$, when $\left\{t_{n}\right\}$ meets $t_{n}-t_{n-1} \neq t_{n+1}-t_{n}$, the signal $x\left(t_{n}\right)$ is called the stagger-period signal, or staggered signal for short. Reference [10] studied Fourier analyses of staggerperiod sequences, which can have infinite periods. In practice, the stagger periods are finite, denoted by $T_{n}=t_{n}$ $t_{n-1}, n \in\left\{1,2, \cdots N_{t}\right\}, N_{t}$ is number of the periods, then $\left\{T_{n}\right\}$ are a set of the finite periods. Given a stagger-period signal 
$\left\{\mathrm{x}\left(\mathrm{t}_{\mathrm{n}}\right)\right\}$, it has $\mathrm{N}_{\mathrm{t}}$ stagger periods, and the other periods repeat the $\mathrm{N}_{\mathrm{t}}$ periods, then its stagger periods are $\mathrm{N}_{\mathrm{t}}$-circular. If $\mathrm{N}_{\mathrm{t}}=1$, it declines to a uniform-period signal; thus, the uniform-period signal is a special case of the stagger-period signals. Suppose that scale of the stagger periods meets $\mathrm{T}_{1}: \mathrm{T}_{2}: \cdots \mathrm{T}_{\mathrm{N}_{\mathrm{t}}}=\mathrm{k}_{1}: \mathrm{k}_{2}: \cdots \mathrm{k}_{\mathrm{N}_{\mathrm{t}}}$, the set of the ordered integers $\left\{\mathrm{k}_{\mathrm{i}}\right\}$ is called the period code or stagger code of $\left\{\mathrm{T}_{\mathrm{n}}\right\}$. If $\left\{\mathrm{k}_{\mathrm{i}}\right\}$ are mutually prime and meet

$$
\tau=\mathrm{T}_{1} / \mathrm{k}_{1}=\mathrm{T}_{2} / \mathrm{k}_{2}=\cdots \mathrm{T}_{\mathrm{N}_{\mathrm{t}}} / \mathrm{k}_{\mathrm{N}_{\mathrm{t}}}
$$

we call the ratio $\tau$ the highest common divisor of these periods; let $\mathrm{T}_{\mathrm{c}}=\sum_{\mathrm{i}=1}^{\mathrm{N}_{\mathrm{t}}} \mathrm{T}_{\mathrm{i}}$, we have $\tau=\mathrm{T}_{\mathrm{c}} / \sum_{\mathrm{i}=1}^{\mathrm{N}_{\mathrm{t}}} \mathrm{k}_{\mathrm{i}}$. Suppose that a $\mathrm{N}_{\mathrm{t}}$-circular stagger-period signal meets (1), it has a spectrum equation [10],

$$
X_{s}(f)=\sum_{n=-\infty}^{\infty} x\left(t_{n}\right) e^{-j 2 \pi f t_{n}} \quad f \in\left[-B_{f} / 2, B_{f} / 2\right]
$$

where $B_{f}=1 / \tau$, referred to as spectrum period of $\left\{x\left(t_{n}\right)\right\}$; the spectrum shape is related to not only the values $\mathrm{T}_{1}, \mathrm{~T}_{2}, \cdots \mathrm{T}_{\mathrm{N}_{\mathrm{t}}}$ but also their order. In the uniform-period case, let the sampling period be $T_{u}$, the spectrum period is $1 / T_{u}$ with frequency axis unit $\mathrm{Hz}$, also called Nyquist interval. In the stagger-period case, let average sampling period be $\mathrm{T}_{\mathrm{a}}$, equal to $\mathrm{T}_{\mathrm{c}} / \mathrm{N}_{\mathrm{t}}$, the spectrum period is extended for a multiple of $\mathrm{R}_{\mathrm{f}}=\sum_{\mathrm{i}=1}^{\mathrm{N}_{\mathrm{t}}} \mathrm{k}_{\mathrm{i}} / \mathrm{N}_{\mathrm{t}}$, called extension factor, so the Nyquist interval is also extended.

A FIR filter working with the stagger-period signal is called the staggered-period FIR filter, denoted by $h_{s}\left(t_{1}\right), 1$ $\in\left\{0,1, \cdots \mathrm{N}_{\mathrm{p}}-1\right\}, \mathrm{N}_{\mathrm{p}}$ filter length. Obviously, its impulse period must match the input signal periods at each input time $t_{n}$. Thus, such a filter is a time-variant system, and it does not hold to use the convolution operation of the discrete-time system to derive the frequency response of the staggered FIR filter. When the impulse periods $\left\{\mathrm{T}_{1}=\mathrm{t}_{1}-\mathrm{t}_{1-1}\right\}$, meet (1), avoiding the frequency response derivation of a discrete-time system [2], we directly define the frequency response of a stagger-period FIR filter as

$$
H_{s}(f)=\sum_{l=-\infty}^{\infty} h_{s}\left(t_{l}\right) e^{-j 2 \pi f t_{l}} \quad f \in\left[-F_{p} / 2, F_{p} / 2\right]
$$

where $F_{p}=1 / \tau$ is called frequency (response) period of the FIR filter, and is equal to the spectrum period $B_{f}$ of $\left\{e^{-j 2 \pi f t_{l}}\right\}$. No doubt, the frequency period is related to $\mathrm{T}_{1}, \mathrm{~T}_{2}, \cdots \mathrm{T}_{\mathrm{N}_{\mathrm{t}}}$. When we identify (3) as the Fourier transform of $\left\{\mathrm{h}_{\mathrm{s}}\left(\mathrm{t}_{\mathrm{l}}\right)\right\}$, we can define the inverse Fourier transform of (3) as

$$
\mathrm{h}_{\mathrm{s}}\left(\mathrm{t}_{\mathrm{l}}\right)=\frac{1}{\mathrm{~B}_{\mathrm{f}}} \int_{-\mathrm{B}_{\mathrm{f}} / 2}^{\mathrm{B}_{\mathrm{f}} / 2} \mathrm{H}_{\mathrm{s}}(\mathrm{f}) \mathrm{e}^{\mathrm{j} 2 \mathrm{mft}} \mathrm{df} \quad \mathrm{l} \in\{0, \pm 1, \cdots\}
$$

From [10], we knew that the stagger-period sequence $\mathrm{e}^{\mathrm{j} 2 \mathrm{\pi ft}}$, $1 \in\{0, \pm 1, \pm 2, \cdots\}$ is normalized and orthogonal in the frequency region $\left[-\mathrm{B}_{\mathrm{f}} / 2, \mathrm{~B}_{\mathrm{f}} / 2\right]$. This yet indicates qualitatively that (3) and (4) can be a valid Fourier transform pair. In order to ensure that the transform pair holds, we need to prove the inverse of each other. Inserting (3) into the rightside of (4), we obtain, through normalized orthogonality of $\left\{\mathrm{e}^{\mathrm{j} 2 \pi \mathrm{ft}} \mathrm{l}\right\}$

$$
\begin{aligned}
h_{s}\left(t_{n}\right) & =\frac{1}{B_{f}} \int_{-B_{f} / 2}^{B_{f} / 2} \sum_{l=-\infty}^{\infty} h_{s}\left(t_{l}\right) e^{j 2 \pi f\left(t_{n}-t_{l}\right)} d f \\
& =\sum_{l=-\infty}^{\infty} h_{s}\left(t_{l}\right) \delta_{t}\left(t_{n}-t_{l}\right) \\
& =h_{s}\left(t_{n}\right)
\end{aligned}
$$

if (3) is uniformly convergent or absolutely convergent. The latter condition is stricter than the former; in practical application, the both conditions are true.

Fig. 1 (a) shows impulse responses of two staggered FIR filters, rectangle functions of amplitude 1; their 5-circular stagger codes are $\mathrm{k}_{1}: \mathrm{k}_{2}: \mathrm{k}_{3}: \mathrm{k}_{4}: \mathrm{k}_{5}=19: 23: 26: 29: 31, \mathrm{~F}_{\mathrm{p}}$ is $15.36 \mathrm{kHz}$; length of one filter is 5 , black color, length of the other filter is 10 , blue color; their average sampling period is $1 / 600$ s. Fig. 1 (b) shows their frequency responses, we can observe that the both responses are Sinc curves; original main-lobes occur at $0 \mathrm{kHz}$, declined main-lobe occur at 0.6 and $1.2 \mathrm{kHz}$. For comparison, we selected two uniform-

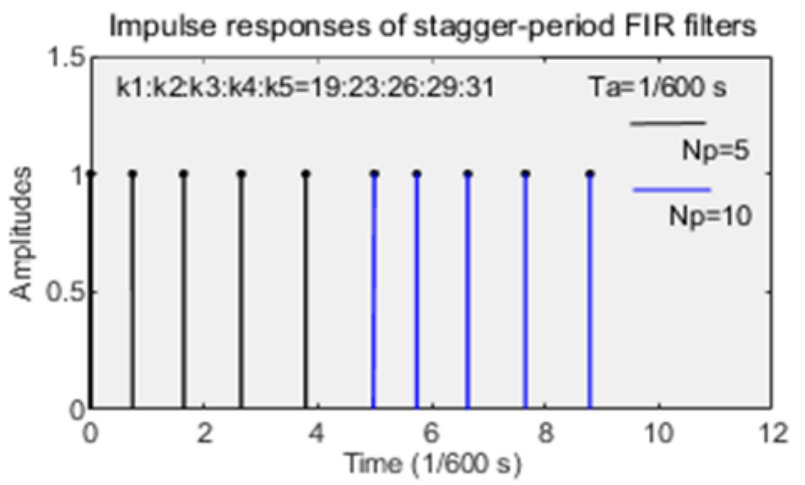

(a) impulse responses

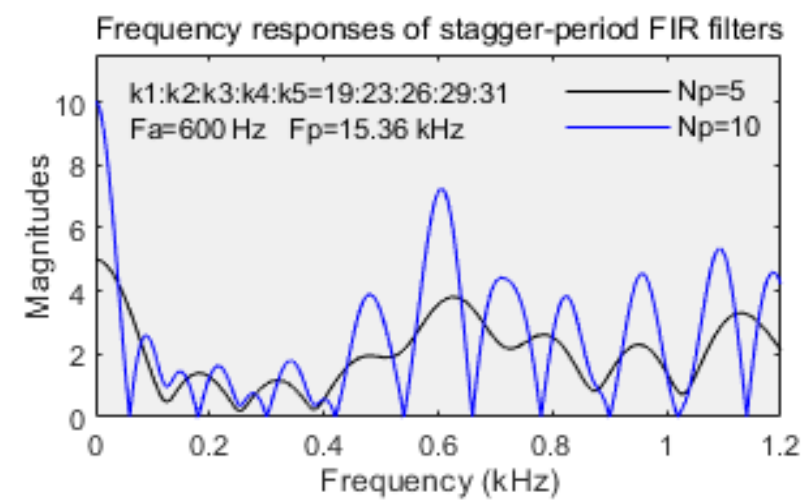

(b) frequency responses

Fig. 1 Two stagger-period FIR filters' impulse and frequency responses

Impulse responses of uniform-period FIR filters

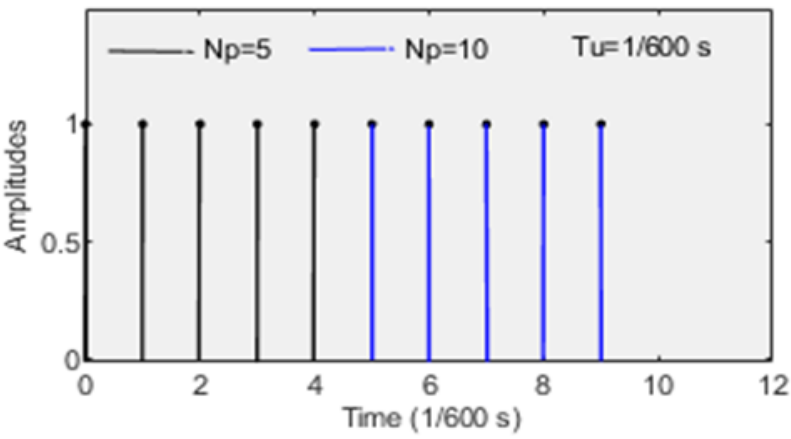

(a) impulse responses

Frequency responses of uniform-period FIR filters

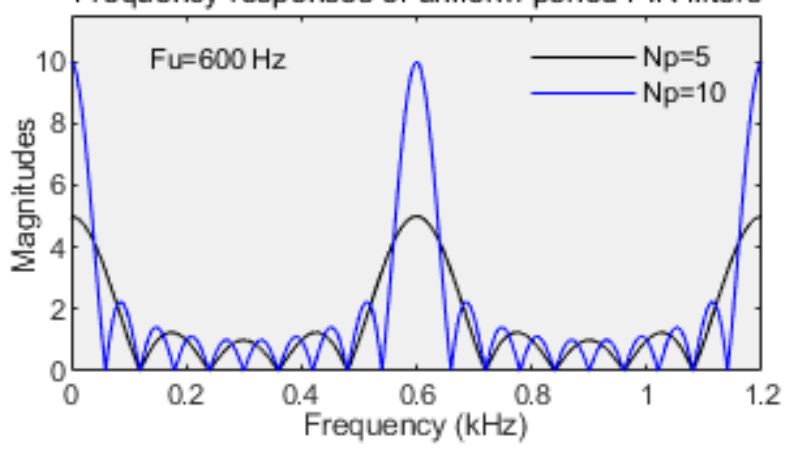

(b) frequency responses

Fig. 2 Two uniform-period FIR filters' impulse and frequency responses 
period sampling period 1/600 s, shown in Fig. 2 (a). Their frequency impulses, the same rectangles and lengths as in Fig. 1 (a), responses are shown in Fig. 2 (b). We can observe that the both responses also are Sinc curves, but the original mainlobes recur at Nyquist frequencies, 0.6 and $1.2 \mathrm{kHz}$. Comparing the four frequency responses in Fig. 1 (b) and Fig. 2 (b), we can find the extension of the frequency periods is the most difference between the stagger-period and uniformperiod frequency responses.

\section{B. Outputs of a stagger-period FIR filter}

Length of a real-world FIR filter always is finite. Given a $\mathrm{N}_{\mathrm{t}}$-circular stagger-period signal $\mathrm{x}\left(\mathrm{t}_{\mathrm{n}}\right), \mathrm{n} \in\{0, \pm 1, \cdots\}$, and impulse response of a staggered FIR filter, $h_{s}\left(\tau_{1}\right), 1 \in\{0,1$, $\left.\cdots \mathrm{N}_{\mathrm{p}}-1\right\}$, we knew in section II.A that at a different $t_{\mathrm{n}}$, the different time set $\left\{\tau_{1}\right\}$ is to be assigned. For example, at $t_{0}$, the periods of the staggered impulse responses, are $\left\{\mathrm{T}_{1}\right.$, $\left.\mathrm{T}_{2}, \cdots \mathrm{T}_{c}\right\}$, but at $\mathrm{t}_{1}$, the periods are $\left\{\mathrm{T}_{2}, \mathrm{~T}_{3}, \cdots \mathrm{T}_{\mathrm{N}_{\mathrm{t}}}, \mathrm{T}_{1}\right\}$. Even if $H_{s}(f)$ is fixed, from (4), the $N_{p}$ impulses vary over $t_{n}$. For rigorousness, we denote $h_{s}\left(\tau_{1}\right)$ by $h_{s}\left(t_{n}, \tau_{1}\right), n \in\{1,2, \cdots\}$, then the output of the staggered FIR filter is derived as

$$
y\left(t_{n}\right)=\sum_{l=0}^{N_{p}-1} x\left(t_{n+1}\right) h_{s}^{*}\left(t_{n}, \tau_{l}\right)
$$

where $*$ is complex conjugation. It is easy to examine that (5) meets the superposition property [2]. Thus, the stagger-period FIR filter also is a linear-time-variant system; but impulse response of the uniform-period filter $\left\{\mathrm{h}_{\mathrm{u}}\left(\tau_{1}\right)\right\}$ does not vary over $\left\{t_{n}\right\}$, and the uniform-period FIR filter is a special case $\left(\mathrm{N}_{\mathrm{t}}=1\right)$ of the stagger-period FIR filter.

Each filter of the $\mathrm{N}_{\mathrm{t}}$-circular staggered filter bank offers a different frequency response even though the difference may be quite mild. This is a property of the stagger-period FIR filter. For example, a lowpass filter has a passband $[0,180]$ $\mathrm{Hz}$, average sampling frequency $600 \mathrm{~Hz}$, length 10. An input signal is of 3-circular stagger periods, whose period code is

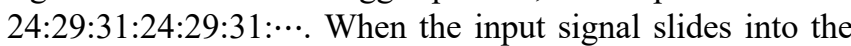
staggered filter, ten periods of the current impulse must match the corresponding ten periods of the input samplings. Fig. 3 shows three frequency responses of the lowpass filters, period code of the 1 st filter is $24: 29: 31: \cdots 24: 29: 31: 24$, black color; period code of the 2nd filter is 29:31: 24: $\cdots 29: 31: 24$ : 29 , blue color; period code of the 3 rd filter is $31: 24$ : 29: $\cdots 31: 24: 29: 31$, red color. We can observe that the three main-lobes in passband almost make no difference, but the sidelobes in the stopbands make big differences. They really present the desired lowpass behaviors.

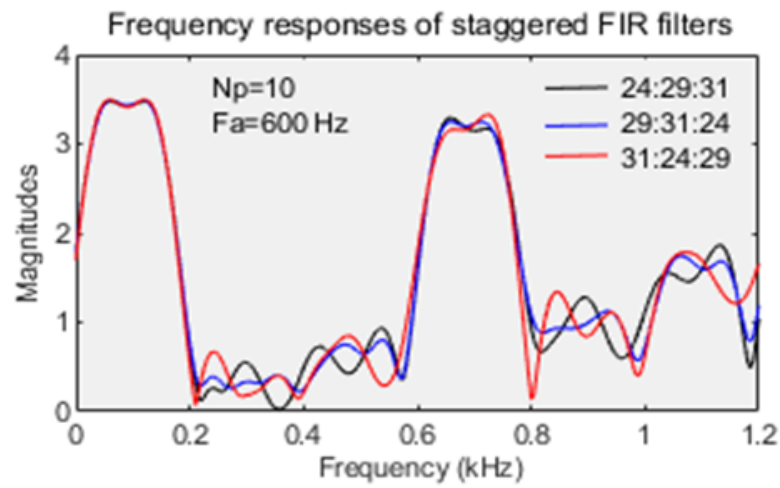

Fig. 3 Time-variant frequency responses of 3-circular stagger-period filters

In the uniform period case, successive outputs of a FIR filter are attached the same phase. However, phase responses of the staggered filters are somewhat different at the successive outputs because of their time-variant impulse property. Then, if the phase characteristic is required in some application, the further research has to be conducted.

Suppose that an input signal is $x\left(t_{n}\right), n \in\{0,1,2, \cdots\}$, and impulse response of a staggered FIR filter is $h_{s}\left(t_{n}, \tau_{l}\right), l \in\{0$, $\left.1, \cdots \mathrm{N}_{\mathrm{p}}-1\right\}$. Since $\left\{\mathrm{h}\left(\mathrm{t}_{\mathrm{n}}, \tau_{1}\right)\right\}$ is time-variant, i.e., $\mathrm{h}_{\mathrm{s}}\left(\mathrm{t}_{\mathrm{n}+1}, \tau_{\mathrm{l}}\right) \neq \mathrm{h}_{\mathrm{s}}\left(\mathrm{t}_{\mathrm{n}}, \tau_{\mathrm{l}}\right)$, (5) is not a conventional convolution equation, and relationship between the output signal spectrum $Y_{s}(f)$ and input signal spectrum $X(f)$ does not meet

$$
\mathrm{Y}_{\mathrm{s}}(\mathrm{f})=\mathrm{H}_{\mathrm{s}}^{*}(\mathrm{f}) \mathrm{X}(\mathrm{f})
$$

From [10], the inverse Fourier transform of (2) is denoted by

$$
x\left(t_{n}\right)=\frac{1}{B_{f}} \int_{-B_{f} / 2}^{B_{f} / 2} X(f) e^{j 2 \pi f t_{n}} d f
$$

Inserting (7) into the right-side of (5), we can derive the staggered FIR filter output as

$$
y\left(t_{n}\right)=\frac{1}{B_{f}} \int_{-B_{f} / 2}^{B_{f} / 2} X(f) H_{s}^{*}\left(t_{n}, f\right) e^{j 2 \pi f t_{n}} d f
$$

Identifying (8) as the inverse Fourier transform of a staggered signal spectrum, we obtain the spectrum of $y\left(t_{n}\right)$,

$$
Y_{s}\left(t_{n}, f\right)=H_{s}^{*}\left(t_{n}, f\right) X(f) \quad n \in\{0, \pm 1, \pm 2, \cdots\}
$$

Thus, the spectrum of the stagger-period FIR filter output also is time-variant even though its input spectrum is timeinvariant. By analysing (9), only if $\mathrm{H}_{s}\left(\mathrm{t}_{n}, \mathrm{f}\right)$, including the amplitude and phase, is independent of $t_{n}$, (6) holds; but this condition is not true for the practical stagger-period filters. However, in a limited frequency region, this condition could be true, e.g., within the passband of Fig.3, then, we can think (6) holds in the limited region.

\section{CONVENTIONAL DESIGNS OF STAGGER-PERIOD FIR FILTERS}

\section{A. Frequency-selective filter designs}

The conventional designs of uniform-period FIR filters mostly utilized the truncation and windowing methods when their requirements are the ideal frequency-selective filters, such as lowpass, high-pass etc. [3]. Given stagger periods and frequency response specifications of a bandpass filter, in terms of its inverse Fourier transform (4), we can design the frequency-selective filters. According to passband center $F_{o}$ and width $\mathrm{B}_{\mathrm{w}}$, the desired frequency response is denoted by a rectangle function,

$$
H_{s}(f)=\left\{\begin{array}{lr}
1 & F_{o}-B_{w} / 2 \leq f \leq F_{o}+B_{w} / 2 \\
0 & \text { otherwise }
\end{array}\right.
$$

After inserting (10) into the right-side of (4) and integrating, the desired impulse response is derived as

$$
\mathrm{h}_{s}\left(\mathrm{t}_{\mathrm{l}}\right)=\frac{\mathrm{B}_{\mathrm{w}}}{2 \mathrm{~F}_{\mathrm{p}}} \operatorname{Sinc}\left(\pi \mathrm{B}_{\mathrm{w}} \mathrm{t}_{\mathrm{l}}\right) \mathrm{e}^{\mathrm{j} 2 \pi \mathrm{F}_{\mathrm{o}} \mathrm{t}_{\mathrm{l}}} \quad \mathrm{l} \in\{0,1, \cdots\}
$$

where constant factor $\mathrm{B}_{\mathrm{w}} / 2 \mathrm{~F}_{\mathrm{p}}$ can be ignored. In practice, the filter length cannot be infinite, we need to truncate the impulse response. After $\left\{h_{s}\left(t_{l}\right)\right\}$ is truncated to length $N_{p}$, the response of the truncated filter approximates the desired $\mathrm{H}_{\mathrm{s}}(\mathrm{f})$. From (11), we can know that (1) the bandpass filter impulse response $\left\{h_{s}\left(t_{l}\right)\right\}$ is a complex Sinc function; if the frequency response is symmetric about the $\mathrm{Y}$ axis, the impulse response is a real part only. (2) The band width determines the interval between the adjacent Sinc zeros, the band center determines the impulse phase response. Fig. 4 shows real and imaginary parts of a staggered bandpass filter, whose 5-circular period code is 19:23:26:29:31, $\mathrm{N}_{\mathrm{p}}$ is $31, \mathrm{~F}_{\mathrm{o}}$ 
is $300 \mathrm{~Hz}, \mathrm{~B}_{\mathrm{w}}$ is $200 \mathrm{~Hz}$, and $\mathrm{F}_{\mathrm{a}}$ is $600 \mathrm{~Hz}$. When the impulse response is truncated, the impulses with high energy are to be selected as possible so that the obtained filter has the most approximated frequency response. From Fig. 4, we can observe that the highest amplitude of Sinc function center is located at $t_{1}=15 \mathrm{~T}_{a}$, not at $t_{1}=0$ as per (11), because the $\left\{\mathrm{h}_{\mathrm{s}}\left(\mathrm{t}_{\mathrm{l}}\right)\right\}$ was shifted backward by 15 periods to fit (5). Fig. 5 shows the frequency response of the filter of Fig.4, black color, the main-lobe is located in the desired passband; the declined main-lobe occurs around $900 \mathrm{~Hz}$. For comparison, in Fig.5, we also show the frequency response of a uniformperiod filter, blue color, which is required to have the same passband specifications as (10). We can observe that the resulting main-lobe is almost the same as the staggered mainlobe; but it entirely recurs at $900 \mathrm{~Hz}$; the staggered sidelobes rise over the uniform-period sidelobes. On the both responses, the jagged Gibbs' oscillation, i.e., the ripple overshoot, occurs. Obviously, such an oscillation can cause adverse effects, such as spectrum distortion; number and height of the ripples are related to length $\mathrm{N}_{\mathrm{p}}$. By experiments, we found that when the length $\mathrm{N}_{\mathrm{p}}$ is short, the oscillation does not occur, but the main-lobes are moon arc; when $\mathrm{N}_{\mathrm{p}}$ gets long, e.g., 31 , the oscillation occurs; when $\mathrm{N}_{\mathrm{p}}$ is extremely long, e.g., 400 or more, the oscillation almost disappears, and the main-lobe approximates the desired passband. In practical FIR filter designs, it is impractical and unnecessary to select quite large $\mathrm{N}_{\mathrm{p}}$. However, the sidelobes' height and the transition band width both decreases with increase of $\mathrm{N}_{\mathrm{p}}$; in order to make transition response steep, $\mathrm{N}_{\mathrm{p}}$ is often selected to be enough large.

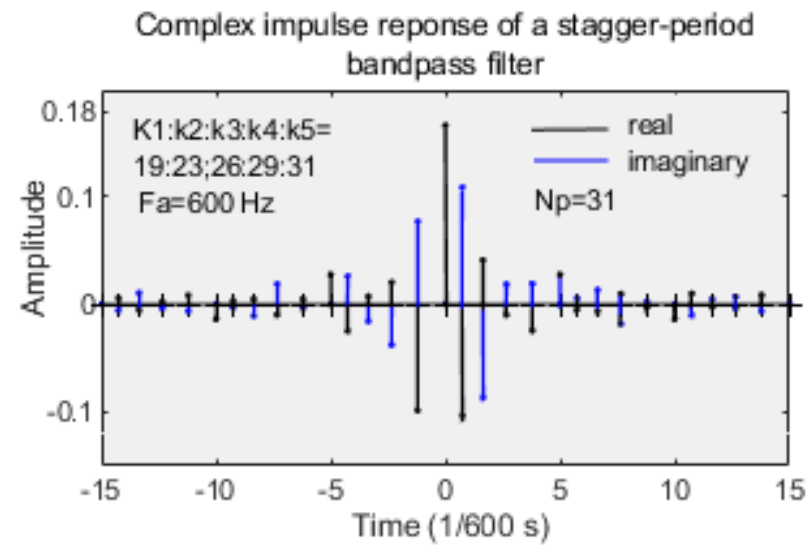

Fig. 4 Impulse response of a stagger-period bandpass filter

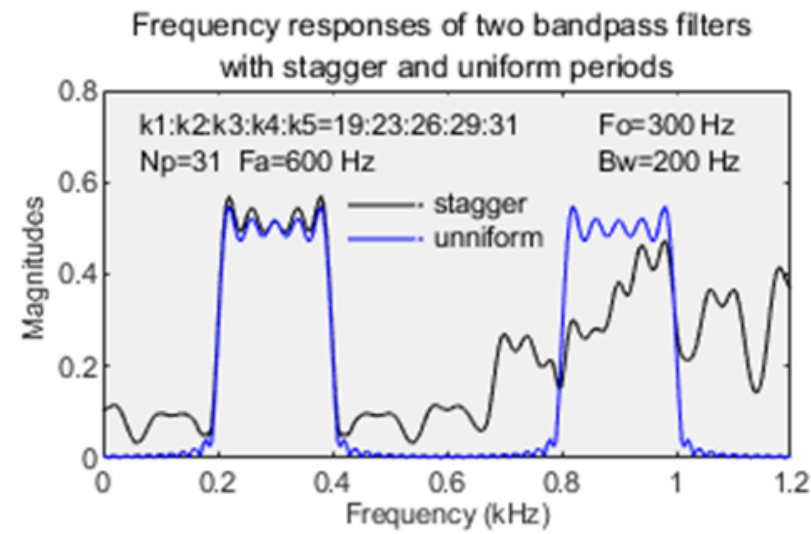

Fig. 5 Frequency responses of two bandpass filters with stagger periods and uniform periods

\section{B. Windowing methods for filter designs}

In the uniform-period FIR filter design, to weaken the Gibbs' oscillation, ones used the windowing procedure. Reference [3] introduced the windowing philosophy to lower undesired ripples, and discussed the features of various window functions. Most of the functions do not relate to the sampling periods, and some windowing functions are easily modified for the stagger-period FIR filter design. The truncation of impulse response in section III.A, in fact, is a rectangular windowing procedure. The rectangle-truncated function for the staggered FIR filters is expressed in terms of

$$
\mathrm{W}_{\mathrm{r}}\left(\mathrm{t}_{\mathrm{k}}\right)=\left\{\begin{array}{lc}
1 & 0 \leq \mathrm{t}_{\mathrm{k}} \leq \mathrm{t}_{\mathrm{N}_{\mathrm{p}}-1} \\
0 & \text { otherwise }
\end{array}\right.
$$

Recall the above application of (12), we found its features: (1) the main-lobe always behaved with the high Gibbs' oscillation in the passband; (2) the sidelobes also shows undesired oscillation. In order to tackle the major oscillation caused by the rectangular window, we here introduce three more window functions: Hamming, Blackman and Kaiser, which resulted from reference [3], and have been modified for stagger-period applications. They are, respectively,

$$
\begin{aligned}
& \mathrm{W}_{\mathrm{h}}\left(\mathrm{t}_{\mathrm{k}}\right)=\left\{\begin{array}{r}
0.54+0.46 \cos \left[\frac{\pi\left(2 \mathrm{t}_{\mathrm{k}}-\mathrm{t}_{\mathrm{N}_{\mathrm{p}}-1}\right)}{\mathrm{t}_{\mathrm{N}_{\mathrm{p}}-1}}\right] \\
0 \leq \mathrm{t}_{\mathrm{k}} \leq \mathrm{t}_{\mathrm{N}_{\mathrm{p}}-1} \\
\text { otherwise }
\end{array}\right. \\
& \mathrm{W}_{\mathrm{b}}\left(\mathrm{t}_{\mathrm{k}}\right)=\left\{\begin{array}{r}
0.42+0.5 \cos \left[\frac{\pi\left(2 t_{k}-\mathrm{t}_{\mathrm{N}_{\mathrm{p}}-1}\right)}{\mathrm{t}_{\mathrm{N}_{\mathrm{p}}-1}}\right] \\
+0.08 \cos \left[\frac{2 \pi\left(2 t_{k}-\mathrm{t}_{\mathrm{N}_{\mathrm{p}}-1}\right)}{\mathrm{t}_{\mathrm{N}_{\mathrm{p}}-1}}\right] \\
0 \leq \mathrm{t}_{\mathrm{k}} \leq \mathrm{t}_{\mathrm{N}_{\mathrm{p}}-1} \\
\text { otherwise. }
\end{array}\right.
\end{aligned}
$$

and

$$
\mathrm{W}_{\mathrm{k}}\left(\mathrm{t}_{\mathrm{k}}\right)=\left\{\begin{array}{r}
\mathrm{I}_{0}\left\{\alpha \sqrt{1-\left[\frac{2\left(t_{k}-\mathrm{t}_{\mathrm{N}-1}\right)}{\mathrm{t}_{\mathrm{N}_{\mathrm{p}}-1}}-1\right]^{2}}\right\} / \mathrm{I}_{0}(\alpha) \\
0 \leq \mathrm{t}_{\mathrm{k}} \leq \mathrm{t}_{\mathrm{N}_{\mathrm{p}-1}} \\
\text { otherwise. }
\end{array}\right.
$$

Obviously, the functions of Hamming (13) and Backman (14) are the cosine sums, but their constant factors are a little different. In Kaiser (15), $\mathrm{I}_{0}(\alpha)$ is the 0th order Bessel function, the parameter $\alpha$ controls window slope, its default value is 0.5 ; the larger the $\alpha$, the steeper the functional slope. The sampling periods of the windows, $\left\{\mathrm{t}_{\mathrm{k}+1}-\mathrm{t}_{\mathrm{k}}\right\}, \mathrm{k} \in\{0,1$, $\left.\cdots \mathrm{N}_{\mathrm{p}}-1\right\}$, are stagger, and must match the filter impulse periods, so the staggered window functions also are timevariant. Fig. 6 shows curves of the three windows' and rectangle functions, whose period codes all are 19:23:26:29: 31 , and circulate to length 31 ; the selected $\alpha$ is 2.5 for steeper Kaiser function. We can observe that the three curves symmetrically drop along slopes, but the rectangular window does instantly; so, the three windows gradually cut levels of the original impulses, rather than that the rectangular window does sharply. By comparing among the three windows, the Kaiser window cuts the levels gradually, the Blackman window, gently, and the Hamming window, in mid way. Fig. 7 shows frequency responses of the filter of Fig. 4, whose impulse levels were cut by the three window functions. By 
comparing to the original frequency response (black) in Fig 5, we observe that the Gibbs' major oscillation on the whole responses disappears; so, the window functions are quite effective. When viewing carefully, the Blackman main-lobe looks a little smoother than the Kaiser main-lobe does, but the Blackman main-lobe deviates from the desired passband a little more than Kaiser main-lobe does; the Hamming response behaves in mid way. Differences of the three frequency responses in Fig. 7 are consistent with the windows' characteristics in Fig. 6.

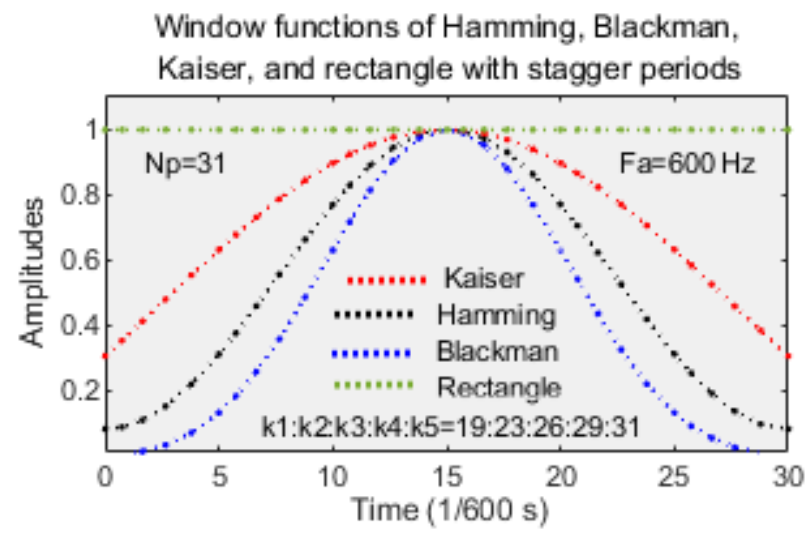

Fig. 6 Functions of four windows with stagger periods

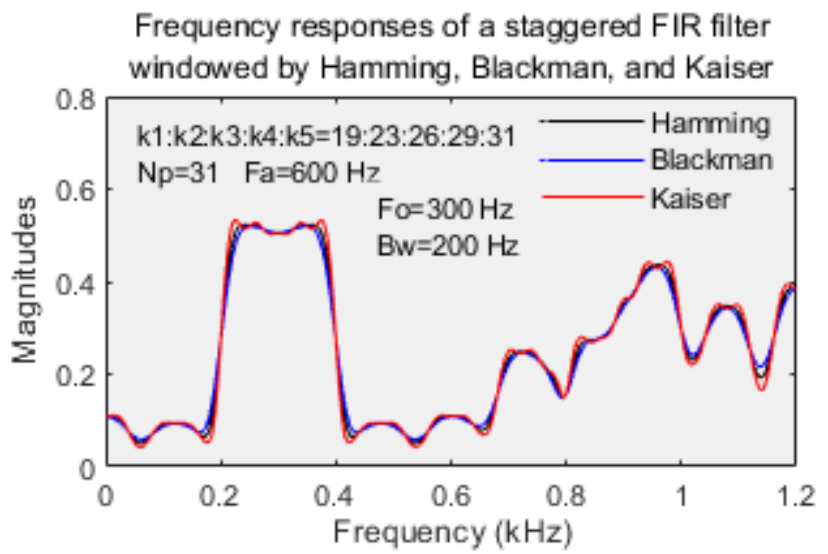

Fig. 7 Frequency responses of a stagger-period high-pass filter windowed by Hamming, Blackman, and Kaiser

\section{OPTIMIZATION DESIGNS OF STAGGER-PERIOD FIR FILTERS}

In section III, we discussed the conventional designs of stagger-period FIR filters, which achieved specifications of the given passband and stopband; then, the designed filters could be used in some situations. Sometimes, it is inconvenient for a user to give appropriate specifications of the passband and stopband so that the obtained filter functions best in the application. For example, when designing a highpass FIR filter with the conventional method, the resulting notch depth depends on the given stopband width and filter length, but a user can not know the accurate relationships beforehand. From the application effectiveness, the stopband notch is directly related to the intensity of interferences. The stronger the interference intensity, the deeper the notch depth. The optimization filter design, unlike the conventional frequency-selective filter design, needs the given spectral intensities, centers and widths of both the input interference and signals, and offers a filter with the optimized notch and main-lobe accordingly.
Suppose that an input signal vector $\mathrm{S}_{\mathrm{d}}=\left[\mathrm{s}_{\mathrm{d}}\left(\mathrm{t}_{0}\right), \mathrm{s}_{\mathrm{d}}\left(\mathrm{t}_{1}\right), \cdots\right.$ $\left.\mathrm{s}_{\mathrm{d}}\left(\mathrm{t}_{\mathrm{Np}-1}\right)\right]^{\mathrm{T}}$ is deterministic, $\mathrm{T}$ is transition; an input interference (clutter plus noise) vector is a stationary process, $\mathrm{Z}_{\mathrm{c}}=\left[\mathrm{z}_{\mathrm{c}}\left(\mathrm{t}_{0}\right), \mathrm{z}_{\mathrm{c}}\left(\mathrm{t}_{1}\right), \cdots \mathrm{z}_{\mathrm{c}}\left(\mathrm{t}_{\mathrm{Np}-1}\right)\right]^{\mathrm{T}}$, with a covariance matrix $\mathrm{M}_{\mathrm{c}}=\mathrm{E}\left\{\mathrm{Z}_{\mathrm{c}} Z_{c}^{\dagger}\right\}, \dagger$ is conjugate transition, and $\mathrm{E}\{\}$ is expectation operator. Note that here and later, the signals and interferences are all complex. Under a criterion of the output signal-to-clutter/interference ratio (SCR) maximum, the filter coefficient vector, $H_{m}=\left[h_{m}\left(t_{0}\right), h_{m}\left(t_{1}\right), \cdots h_{m}\left(t_{N p-1}\right)\right]^{T}$, can easily be derived as the solution of the following equation group [11],

$$
\mathrm{M}_{\mathrm{c}} \mathrm{H}_{\mathrm{m}}=\mathrm{S}_{\mathrm{d}} \text { or } \mathrm{H}_{\mathrm{m}}=\mathrm{M}_{\mathrm{c}}^{-1} \mathrm{~S}_{\mathrm{d}}
$$

The conditions and operation of this optimized filter $\mathrm{H}_{\mathrm{m}}$ are similar to those of a matched filter in color noise [12]. So, we call this solution of (16) the match algorithm. The criterion of SCR maximum is equivalent to Neyman-Pearson criterion of detection probability maximum if the interference process is of a Gaussian probability density. When the input interference is in a low-frequency region, and the input signals cover a wide high-frequency region, we need to design a high-pass filter to increase SCR. Plus, when the signal sampling frequency is not allowed high enough, but we need to detect the signals located beyond the sampling frequency region, the stagger-period technology has to be utilized. As an example, the deterministic signal $\mathrm{S}_{\mathrm{d}}$ occupies the high frequencies, instead of a single frequency, thus, a mean signal vector is to be assigned [5]. Suppose that the signal vector, $\left\{\exp \left(\mathrm{j} 2 \pi \mathrm{ft}_{\mathrm{i}}\right)\right\}, \mathrm{i} \in\left\{0,1, \ldots \mathrm{N}_{\mathrm{p}}-1\right\}, \mathrm{t}_{0}=0$, is stationary and ergodic, and probability density of the frequency $\mathrm{f}$ is uniform,

$$
P_{t}(f)=\left\{\begin{array}{lr}
1 /\left[F_{h 2}-F_{h 1}\right] & F_{h 1} \leq f \leq F_{h 2} \\
0 & \text { otherwise. }
\end{array}\right.
$$

where $\left[F_{h 1}, F_{h 2}\right]$ is the high-frequency region. We derived elements of the mean signal vector $S_{d}$ as

$$
\begin{aligned}
E\left\{s_{d}\left(t_{i}\right)\right\}=\operatorname{Sinc}\left[\pi t_{i}\left(F_{h 2}-F_{h 1}\right)\right] e^{j \pi t_{i}\left(F_{h 1}+F_{h 2}\right)} & i \in\left\{0,1, \ldots N_{p}-1\right\}
\end{aligned}
$$

Similarly, suppose that the input interference is a stationary and ergodic process, and its power spectrum density (PSD) is a rectangle function in the low-frequency region $\left[0, \mathrm{~F}_{12}\right]$,

$$
\mathrm{PS}_{\mathrm{d}}(\mathrm{f})= \begin{cases}1 & 0<\mathrm{f} \leq \mathrm{F}_{12} \\ 0 & \text { otherwise. }\end{cases}
$$

For a stagger-period stationary sequence, its auto-correlation function is the inverse Fourier transform of its PSD function [10]. Elements of the covariance matrix $M_{c}$ were derived as

$$
\begin{array}{r}
E\left\{z_{c}\left(t_{i}\right) z_{c}\left(t_{j}\right)\right\}=\frac{F_{12}}{B_{\mathrm{f}}} \operatorname{Sinc}[ \\
\left.\pi F_{12}\left(t_{i}-t_{j}\right)\right] e^{j \pi F_{12}\left(t_{i}-t_{j}\right)} \\
i, j \in\left\{0,1, \ldots N_{p}-1\right\}
\end{array}
$$

where constant factor $\mathrm{F}_{12} / \mathrm{B}_{\mathrm{f}}$ could be ignored. Suppose that $\mathrm{F}_{12}$ in (19) is $100 \mathrm{~Hz}$; in (17), $\mathrm{F}_{\mathrm{h} 1}$ is $100 \mathrm{~Hz}$, and $\mathrm{F}_{\mathrm{h} 2}$ is 1200 Hz. We designed three high-pass filters with the specifications by (16). Fig. 8 (a) shows frequency responses of the filters, $\mathrm{N}_{\mathrm{p}}=10$, and the average sampling frequency $\mathrm{F}_{\mathrm{a}}=1200 \mathrm{~Hz}$; period code is $\mathrm{k} 1: \mathrm{k} 2: \mathrm{k} 3: \mathrm{k} 4: \mathrm{k} 5=13: 15: 12: 17: 11$, the impulse periods were circularly used for length 10 , the black, blue, and red curves resulted from clutter-to-noise ratios (CNRs) 28, 38, and $48 \mathrm{~dB}$, respectively. For comparison, Fig. 8 (b) shows frequency responses of the corresponding three uniform-period high-pass filters, $\mathrm{N}_{\mathrm{p}}=10$, sampling frequency $\mathrm{F}_{\mathrm{u}}=1200 \mathrm{~Hz}$. The signal and interference have the same spectral parameters as in the stagger-period 
case. We can observe that (1) in the both figures, three notches of different depths are formed for the different CNRs; the higher the clutter power, the deeper the notch; the frequency responses in the high-pass and beyond are about 50 to $65 \mathrm{~dB}$ higher than the stopband notches. (2) In Fig. 8 (a), the notches in clutter spectrum region do not recur at the intervals of 1200 and $2400 \mathrm{~Hz}$, but in Fig. 8 (b), the notches in clutter spectrum region entirely recurred at the Nyquist intervals.

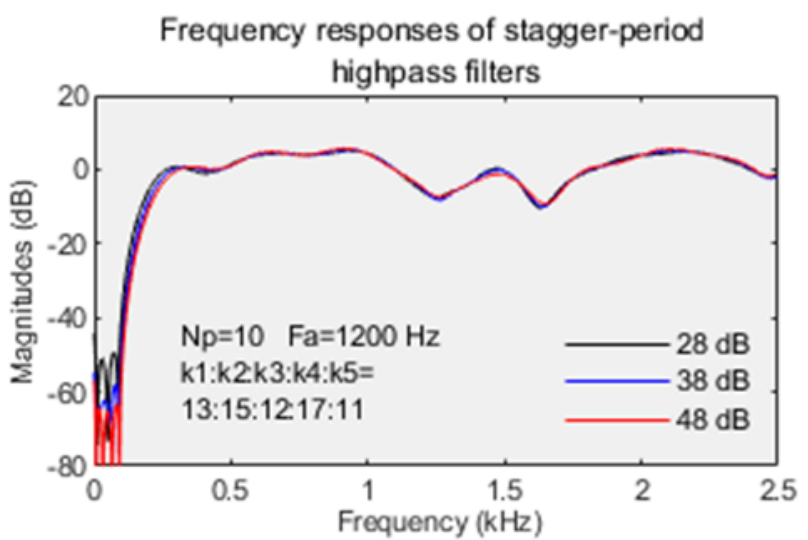

(a) stagger-period

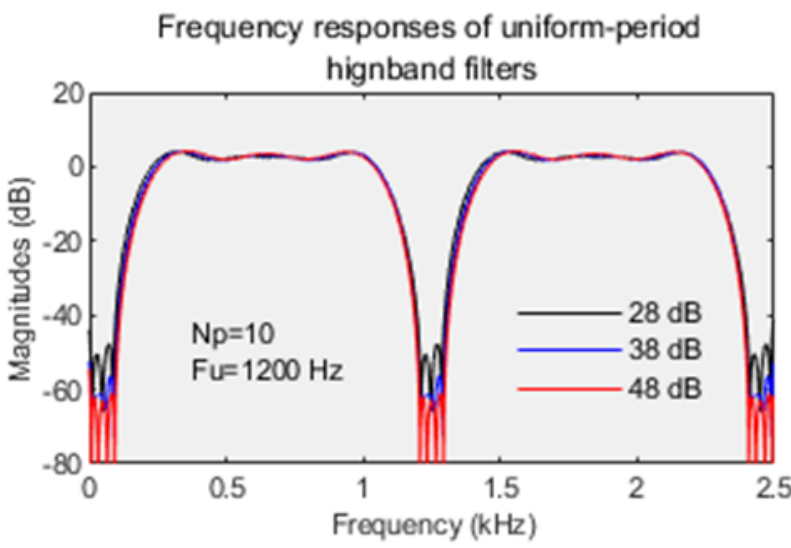

(b) uniform-period

Fig. 8 Frequency responses of three high-pass filters with stagger periods and uniform periods

The stager-period high-pass filters are able to detect targets in the region beyond high-pass, but the frequency responses are fluctuant in a certain degree. By calculating, the peakvalley max value in the passband is $14.6 \mathrm{~dB}$. To balance the signal detection probability, we need to decrease this value. The sum of several successive filters' outputs can flatten the response curves. Fig. 9 (a) shows the composite response of five high-pass filters. The peak-valley value was decreased to $8.2 \mathrm{~dB}$ after the sum. The staggered frequency period is calculated as $1200 \mathrm{~Hz} \times \sum_{i=1}^{5} \mathrm{k}_{\mathrm{i}} / 5=16.32 \mathrm{kHz}$; the extended Nyquist interval just is confirmed. Fig. 9 (b) shows the same composite response, except that the $\mathrm{X}$ axis was zoomed in, only for clear peaks and valleys. Such a characteristic of the stagger-period filters is quite helpful to conquer the so-called missing alarm. They can be used as Doppler filters to reject weather and low-speed clutters while detecting high speed targets in an airport.

\section{APPLICATION OF STAGGER-PERIOD FIR FILTERS}

Generally, return waves of a surveillance radar includes desired aircraft echoes, and various undesired clutters from

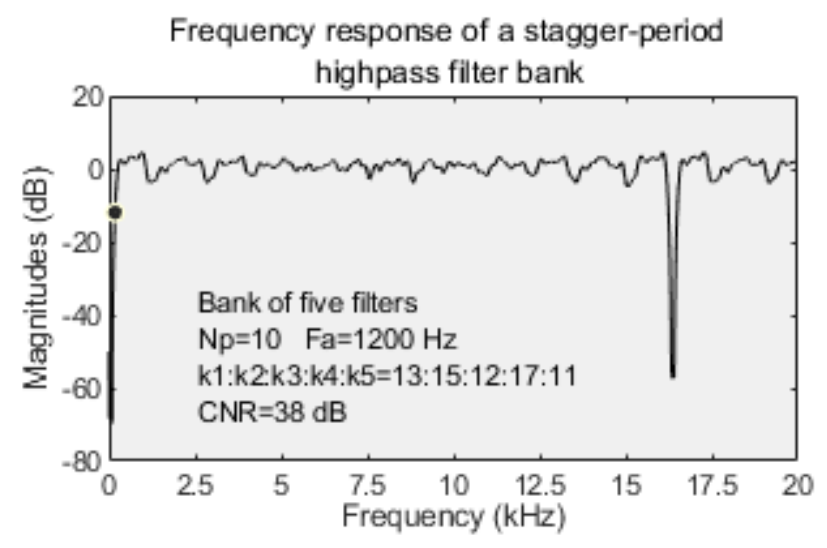

(a) frequency range of 0 to $20 \mathrm{kHz}$

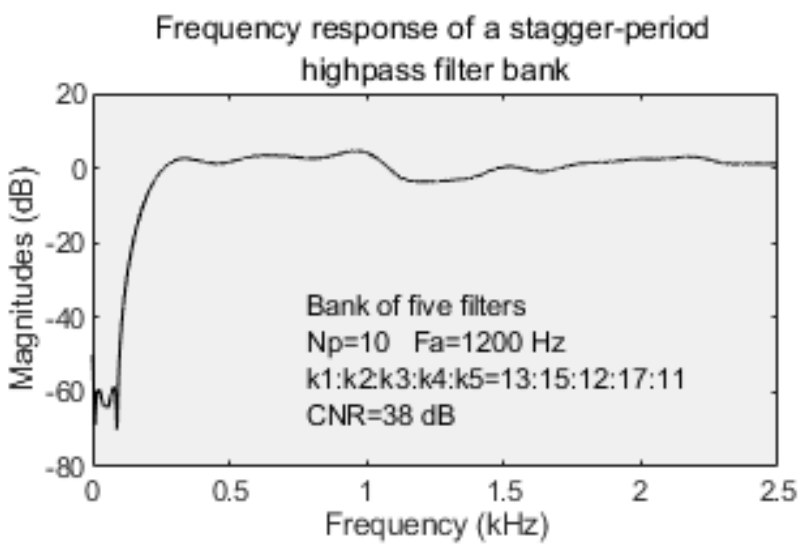

(b) frequency range of 0 to $2.5 \mathrm{kHz}$

Fig. 9 Frequency responses of five stagger-period high-pass filters in a Doppler radar

terrain, forest, sea, and weather etc.; whether an aircraft return or clutters are affected by Doppler shift [6]. Return signals of the relatively moving objects are modulated to Doppler frequency, which is calculated by $F_{d}=2 F_{t} V_{d} / C$, where $F_{t}$ is carrier frequency, $\mathrm{V}_{\mathrm{d}}$ is relative velocity of a moving object to the radar, and C is light speed. In the early years, most MTI radars utilized uniform-period FIR filters to increase SCR. By means of Doppler frequency difference between the desired signal and undesired clutter, an MTI radar can differentiate the overlapped both, and detects the target effectively. However, the frequency response of the uniform-period filter recurs in the intervals of PRF; so does the notch in the clutter spectrum region. Thus, the target signals around a multiple of PRF are rejected. This is the so-called blind velocity problem. If the PRF increases, the blind speed can be eliminated, but an ambiguous range of the target may occur. The unambiguous range of the uniform-period filter is calculated by $\mathrm{CT}_{\mathrm{r}} / 2, \mathrm{~T}_{\mathrm{r}}$ is pulse period; and the unambiguous speed (1st blind speed), by $\lambda / 2 \mathrm{~T}_{\mathrm{r}}, \lambda$ is carrier wave length. For example, $\mathrm{PRF}$ of a radar is $360 \mathrm{~Hz}$, then its blind range is $416.7 \mathrm{~km}$; for $\mathrm{S}$ band carrier of $3000 \mathrm{MHz}$, the first blind speed is $18 \mathrm{~m} / \mathrm{s}$. Obviously, velocities of the current aircrafts and missiles are far higher than $18 \mathrm{~m} / \mathrm{s}$.

Many experts researched approaches to conquer the blind speed problem, and developed technologies. One of them is the stagger-period pulses and coordinated Doppler filters. When designing such filters, they used a criterion: improvement factor (IF) maximum, $\mathrm{IF}=$ output $\mathrm{SCR} /$ input $\underline{\mathrm{SCR}}$. Without loss of generalization, we assign that the input signal and clutter have power unity, then, the IF maximum is 
equivalent to the output SCR maximum. Suppose that receiving times of the stagger-period pulses are $\left\{t_{n}\right\}, n \in\{0$, $1, \cdots\}$, and the column vector of the input target signal is $S_{d}=\left[s_{d}\left(t_{0}\right), s_{d}\left(t_{1}\right), \cdots s_{d}\left(t_{N_{p}-1}\right)\right]^{T}$; the column vector of the input clutter plus noise is $\mathrm{Z}_{\mathrm{c}}=\left[\mathrm{z}_{\mathrm{c}}\left(\mathrm{t}_{0}\right), \mathrm{z}_{\mathrm{c}}\left(\mathrm{t}_{1}\right), \cdots \mathrm{z}_{\mathrm{c}}\left(\mathrm{t}_{\mathrm{N}_{\mathrm{p}}-1}\right)\right]^{\mathrm{T}}$; the FIR filter coefficient vector is $H_{s}=\left[h_{s}\left(t_{0}\right), h_{s}\left(t_{1}\right), \cdots\right.$ $\left.h_{s}\left(t_{N_{p}-1}\right)\right]^{T}$. Then, the output powers of the target signal and clutter plus noise are, respectively,

$$
\mathrm{P}_{\mathrm{s}}=\mathrm{E}\left\{\left|\mathrm{H}_{\mathrm{s}}^{\dagger} \mathrm{S}_{\mathrm{d}}\right|^{2}\right\}=\mathrm{H}_{\mathrm{s}}^{\dagger} \mathrm{M}_{\mathrm{d}} \mathrm{H}_{\mathrm{s}}
$$

and

$$
\mathrm{P}_{\mathrm{c}}=\mathrm{E}\left\{\left|\mathrm{H}_{\mathrm{s}}^{\dagger} \mathrm{Z}_{\mathrm{c}}\right|^{2}\right\}=\mathrm{H}_{\mathrm{s}}^{\dagger} \mathrm{M}_{\mathrm{c}} \mathrm{H}_{\mathrm{s}}
$$

where $M_{d}=E\left\{S_{d} S_{d}^{\dagger}\right\}$ and $M_{c}=E\left\{Z_{c} Z_{c}^{\dagger}\right\}$ are $N_{p} \times N_{p}$ covariance matrices of the signal and interference vectors, respectively. The output SCR is equal to $\mathrm{H}_{s}^{\dagger} \mathrm{M}_{d} \mathrm{H}_{\mathrm{s}} / \mathrm{H}_{\mathrm{s}}^{\dagger} \mathrm{M}_{\mathrm{c}} \mathrm{H}_{\mathrm{s}}$. As an example, pulse parameters of a surveillance radar are average PRF is $360 \mathrm{~Hz}$, and the period code is 25:29:26:28:30. By means of section II.A, the pulsetransmitted periods were calculated as $\mathrm{T}_{1}=2.516$, $\mathrm{T}_{2}=2.919, \mathrm{~T}_{3}=2.617, \mathrm{~T}_{4}=2.818$, and $\mathrm{T}_{5}=3.019 \mathrm{~ms}$. Using classic matrix theory can derive the following stagger-period algorithms to optimize the MTI filter designs.

\section{A. Eigenvalue algorithm}

This algorithm is used under the conditions: the input signal and clutter are both stationary stochastic processes. Reference [5] early proved that the solution of $\mathrm{H}_{\mathrm{s}}^{\dagger} \mathrm{M}_{\mathrm{d}} \mathrm{H}_{\mathrm{s}} /$ $\mathrm{H}_{\mathrm{s}}^{\dagger} \mathrm{M}_{\mathrm{c}} \mathrm{H}_{\mathrm{s}}$ maximum was a solution of the generalized eigenvalue problem,

$$
\mathrm{M}_{\mathrm{d}} \mathrm{H}_{\mathrm{gi}}=\lambda_{\mathrm{gi}} \mathrm{M}_{\mathrm{c}} \mathrm{H}_{\mathrm{gi}} \text {, }
$$$$
\mathrm{i} \in\left\{0,1, \cdots \mathrm{N}_{\mathrm{p}}-1\right\}
$$
which has $\mathrm{N}_{\mathrm{p}}$ eigenvalues $\left\{\lambda_{\mathrm{gi}}\right\}$ and $\mathrm{N}_{\mathrm{p}}$ eigenvectors $\left\{\mathrm{H}_{\mathrm{gi}}\right\}$. The eigenvector $\mathrm{H}_{\mathrm{gi}}$ corresponding to the largest eigenvalue is the optimal filter coefficient vector $\mathrm{H}_{\mathrm{s}}$. Further, [4] proved that when target Doppler frequencies occupies the whole frequency region $[0, \mathrm{PRF}],(23)$ was simplified into an ordinary eigenvalue problem,

$$
\mathrm{M}_{\mathrm{c}} \mathrm{H}_{\mathrm{ei}}=\lambda_{\mathrm{i}} \mathrm{H}_{\mathrm{ei}} \quad \mathrm{i} \in\left\{0,1, \cdots \mathrm{N}_{\mathrm{p}}-1\right\}
$$

which also has $N_{p}$ eigenvalues $\left\{\lambda_{i}\right\}$ and $N_{p}$ eigenvectors $\left\{\mathrm{H}_{\mathrm{ei}}\right\}$. The eigenvector $\mathrm{H}_{\mathrm{ei}}$ corresponding to the least eigenvalue is the optimal filter coefficient vector $H_{s}$. Calculation of (23) was more complicated than that of (24); however, two IFs resulting from (23) and (24) are quite close in the MTI filter design. So, designers always applied (24) to design the MTI filters. It is impossible to directly calculate the elements of the matrices $\mathrm{M}_{\mathrm{d}}$ and $\mathrm{M}_{\mathrm{c}}$. A priori, we were always aware of PSD knowledge of the target signals and the interfering clutters. Alternatively, we calculate their staggerperiod auto-correlation sequences through their PSD. Usually, PSD of the target stationary process was supposed to be the rectangle function, e.g.,

$$
\mathrm{PS}_{\mathrm{s}}(\mathrm{f})=\left\{\begin{array}{rr}
1 & -360 \mathrm{~Hz} \leq \mathrm{f} \leq 360 \mathrm{~Hz} \\
0 & \text { otherwise. }
\end{array}\right.
$$

where minus frequencies represent reverse flying of targets. Auto-correlation function of the target stationary process is the inverse Fourier transform of (25). Completing the derivation in a simmilar way to (20), we obtained

$$
\mathrm{E}\left\{\mathrm{s}_{\mathrm{d}}\left(\mathrm{t}_{\mathrm{i}}\right) \mathrm{s}_{\mathrm{d}}\left(\mathrm{t}_{\mathrm{j}}\right)\right\}=\frac{720}{\mathrm{~B}_{\mathrm{f}}} \operatorname{Sinc}\left[720 \pi\left(\mathrm{t}_{\mathrm{i}}-\mathrm{t}_{\mathrm{j}}\right)\right] \mathrm{e}^{\mathrm{j} 720 \pi\left(\mathrm{t}_{\mathrm{i}}-\mathrm{t}_{\mathrm{j}}\right)}
$$

where constant factor $720 / \mathrm{B}_{\mathrm{f}}$ could be ignored. Usually, the clutter sources includes terrain clutter and weather clutter.
PSDs of both the clutters are supposed to be Gaussian function,

$$
\mathrm{PS}_{\mathrm{c}}(\mathrm{f})=\mathrm{P}_{c} \exp \left[\frac{-\left(\mathrm{f}-\mathrm{F}_{\mathrm{c}}\right)^{2}}{2 \mathrm{D}_{c}^{2}}\right]
$$

where $\mathrm{P}_{c}$ is clutter spectrum power, $\mathrm{F}_{c}$ is spectrum center, and $\mathrm{D}_{c}$ is spectrum standard variance. The inverse Fourier transform of (27) is also a Gaussian function, so, the staggerperiod auto-correlation matrices of both the clutters were derived as

$$
\mathrm{E}\left\{\mathrm{z}_{\mathrm{c}}\left(\mathrm{t}_{\mathrm{i}}\right) \mathrm{z}_{\mathrm{c}}\left(\mathrm{t}_{\mathrm{j}}\right)\right\}=\mathrm{P}_{c} \mathrm{e}^{\mathrm{j} 2 \pi \mathrm{F}_{\mathrm{c}}\left(\mathrm{t}_{\mathrm{i}}-\mathrm{t}_{\mathrm{j}}\right)} \exp \left[\frac{-\left(\mathrm{t}_{\mathrm{i}}-\mathrm{t}_{\mathrm{j}}\right)^{2}}{2 \pi^{2} \mathrm{D}_{c}^{2}}\right]
$$

As a design example, we need to select some parameters: for the terrain clutter, $F_{g}=0 \mathrm{~Hz}, \mathrm{D}_{\mathrm{g}}=7.2 \mathrm{~Hz}$, and $\mathrm{P}_{\mathrm{g}}=55 \mathrm{~dB}$ relative to the thermal noise; for the weather clutter, $F_{w}=72 \mathrm{~Hz}$, $\mathrm{D}_{\mathrm{w}}=10.8 \mathrm{~Hz}$, and $\mathrm{P}_{\mathrm{w}}=30 \mathrm{~dB}$; the average PRF is $360 \mathrm{~Hz}$. Fig. 10 (a) and (b) show frequency responses of the optimized filters with the eigenvalue algorithm (23), blue color, where

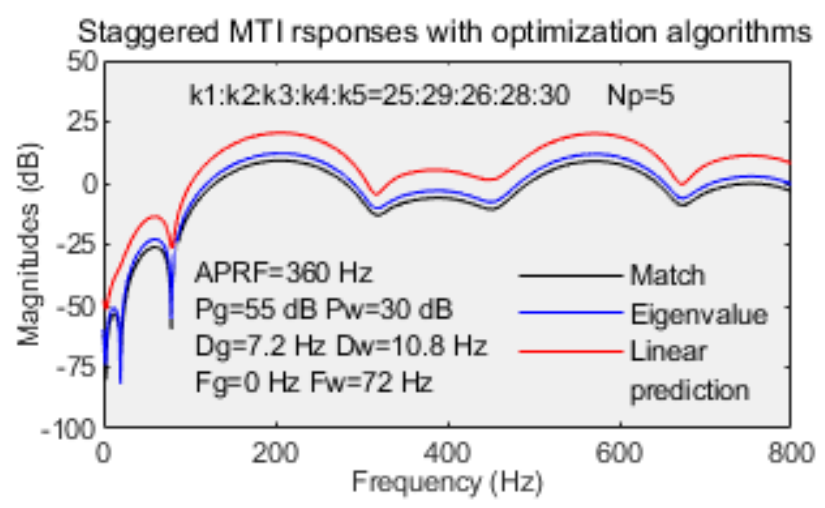

\begin{tabular}{|c|c|c|c|c|}
\hline \multirow{3}{*}{ Algorithms } & \multicolumn{4}{|c|}{ Improvement factors $(\mathrm{dB})$} \\
\hline & \multicolumn{2}{|c|}{ Stagger-period } & \multicolumn{2}{|c|}{ Uniform-period } \\
\hline & $\mathrm{N}_{\mathrm{p}}=5$ & $\mathrm{~N}_{\mathrm{p}}=10$ & $\mathrm{~N}_{\mathrm{p}}=5$ & $\mathrm{~N}_{\mathrm{p}}=10$ \\
\hline Eigenvalue & 50.1 & 55.0 & 50.1 & 55.0 \\
\hline Match & 50.1 & 54.8 & 50.1 & 54.8 \\
\hline $\begin{array}{c}\text { Linear } \\
\text { prediction }\end{array}$ & 49.5 & 52.5 & 49.5 & 52.6 \\
\hline \multirow{2}{*}{ Conditions } & \multicolumn{4}{|c|}{ Terrain clutter and weather clutter } \\
\hline & \multicolumn{2}{|c|}{$\begin{array}{l}\mathrm{k} 1: \mathrm{k} 2: \mathrm{k} 3: \mathrm{k} 4: \mathrm{k} 5= \\
25: 29: 26: 28: 30\end{array}$} & \multicolumn{2}{|c|}{$\mathrm{PRF}=360 \mathrm{~Hz}$} \\
\hline
\end{tabular}

(a) $\mathrm{N}_{\mathrm{p}}=5$

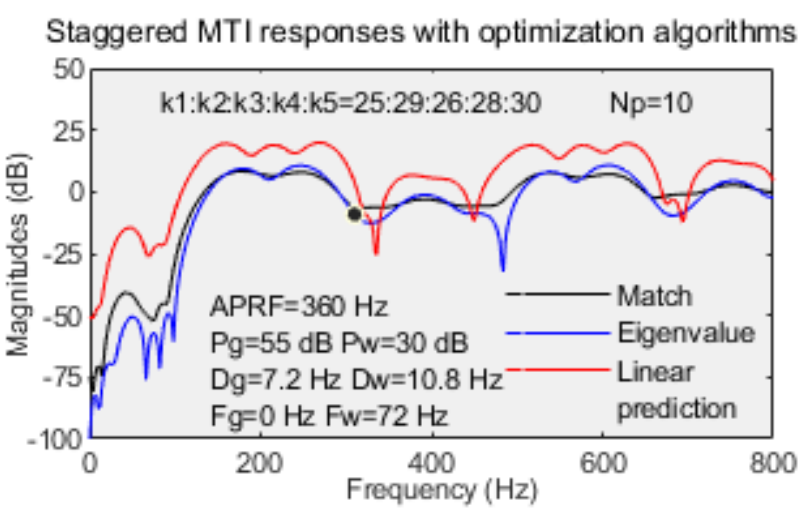

(b) $\mathrm{N}_{\mathrm{p}}=10$

Fig. 10 Frequency responses of stagger-period MTIs with three optimization algorithms

Table I Improvement factors of the stagger-period and uniform-period MTI filters with three optimization algorithms 
$\mathrm{N}_{\mathrm{p}}=5$ and $\mathrm{N}_{\mathrm{p}}=10$, respectively. The IFs resulting from this algorithm were listed in Table I. We can find that the IFs of the staggered and uniform-period filters are equal.

\section{B. Match algorithm}

In section IV, we described the match algorithm (16), and discussed a high-pass filter example. Now, we use this algorithm to design MTI filters. The target signal $S_{d}$ is required to be a deterministic signal, then denoted by $E\left\{\left[s_{d}\left(t_{0}\right), s_{d}\left(t_{1}\right), \cdots s_{d}\left(t_{N_{p}-1}\right)\right]^{T}\right\}, s_{d}\left(t_{i}\right)=\exp \left(j 2 \pi f t_{i}\right), i \in\{0$, $1, \cdots \mathrm{N}_{\mathrm{p}}-1$. Supposed that the target signal frequency $\mathrm{f}$ is distributed uniformly within a region $[-360,360] \mathrm{Hz}$, and in terms of (18), elements of the mean signal vector $S_{d}$ were derived as

$$
\mathrm{E}\left\{\mathrm{s}_{\mathrm{d}}\left(\mathrm{t}_{\mathrm{i}}\right)\right\}=\operatorname{Sinc}\left(720 \pi \mathrm{t}_{\mathrm{i}}\right) \quad \mathrm{i} \in\left\{0,1, \cdots \mathrm{N}_{\mathrm{p}}-1\right\}
$$

where $\left\{t_{i}\right\}$ is stagger sampling times. The terrain and weather clutters' model and parameters were selected the same as in the eigenvalue algorithm. Thus, elements of the $M_{c}$ were also calculated in terms of (28). The filter coefficient vector $\mathrm{H}_{\mathrm{m}}=\left[\mathrm{h}_{\mathrm{m}}\left(\mathrm{t}_{0}\right), \mathrm{h}_{\mathrm{m}}\left(\mathrm{t}_{1}\right), \cdots \mathrm{h}_{\mathrm{m}}\left(\mathrm{t}_{\mathrm{N}_{\mathrm{p}-1}}\right)\right]^{\mathrm{T}}$ was solved in terms of (16). The obtained MTI filters' frequency responses are showed in Fig. 10 (a) and (b), black color, where $\mathrm{N}_{\mathrm{p}}=5$ and $\mathrm{N}_{\mathrm{p}}=10$, respectively. We can observe that in (a), the whole black response is quite close to that eigenvalue blue response; in (b), the match black notch is a few $\mathrm{dB}$ higher than the eigenvalue blue notch, but the black main-lobe fluctuation is less. The IFs resulting from the match algorithm were listed in Table I, and are equal to or $0.2 \mathrm{~dB}$ lower than the IFs from the eigenvalue algorithm.

\section{Linear prediction algorithm}

In the case of uniform-period sequences, linear prediction (LP) theories were long-established [12], [13], but when the LP filter is used for the MTI, it still encounters the blind speed problem. So, the relevant theories needed to be modified to fit the stagger-period sequences. This algorithm's applied condition is no target signal except stationary interferences in the predicted sequence. Suppose that the staggered interference vector is $Z_{c}=\left[z_{c}\left(t_{1}\right), z_{c}\left(t_{2}\right), \cdots z_{c}\left(t_{N_{p}-1}\right)\right]^{T}$, length $\mathrm{N}_{\mathrm{p}}-1$, excluding $\mathrm{z}_{\mathrm{c}}\left(\mathrm{t}_{0}\right)$; and a stagger-period LP filter vector is $\mathrm{H}_{\mathrm{lp}}=\left[\mathrm{h}_{\mathrm{lp}}\left(\mathrm{t}_{1}\right), \mathrm{h}_{\mathrm{lp}}\left(\mathrm{t}_{2}\right), \cdots \mathrm{h}_{\mathrm{lp}}\left(\mathrm{t}_{\mathrm{N}_{\mathrm{p}}-1}\right)\right]^{\mathrm{T}}, \mathrm{h}_{\mathrm{lp}}\left(\mathrm{t}_{0}\right)=1$, which predicts the $\mathrm{z}_{\mathrm{c}}\left(\mathrm{t}_{0}\right)$. This prediction was referred to as one-step backward prediction, and the error caused by the LP filter is

$$
\mathrm{e}\left(\mathrm{t}_{0}\right)=\mathrm{z}_{\mathrm{c}}\left(\mathrm{t}_{0}\right)-\mathrm{H}_{\mathrm{lp}}^{\dagger} \mathrm{z}_{\mathrm{c}}
$$

Given that the interference covariance matrix $\mathrm{M}_{\mathrm{c}}$, its element $\mathrm{E}\left\{\mathrm{z}_{\mathrm{c}}\left(\mathrm{t}_{\mathrm{i}}\right) \mathrm{z}_{\mathrm{c}}^{*}\left(\mathrm{t}_{\mathrm{j}}\right)\right\}, \mathrm{i}, \mathrm{j} \in\left\{1,2, \cdots \mathrm{N}_{\mathrm{p}}-1\right\}$, and the interference covariance vector $\mathrm{R}_{\mathrm{c}}$, its elements $\mathrm{E}\left\{\mathrm{z}_{\mathrm{c}}\left(\mathrm{t}_{0}\right) \mathrm{z}_{\mathrm{c}}^{*}\left(\mathrm{t}_{\mathrm{i}}\right)\right\}, \mathrm{i} \in\{1$, $\left.2, \cdots \mathrm{N}_{\mathrm{p}}-1\right\}$; taking $\mathrm{E}\left\{\left|\mathrm{e}\left(\mathrm{t}_{0}\right)\right|^{2}\right\}$ minimum as the criterion, the stagger-period Yule-Walker equation can be derived as

$$
\mathrm{M}_{\mathrm{c}} \mathrm{H}_{\mathrm{lp}}=\mathrm{R}_{\mathrm{c}}
$$

By means of the uniform-period orthogonality theory [12], we proved that (31) holds in the stagger-period case. For comparison purpose, we selected the same clutter model and parameters as those in sections V.A and V.B, the elements of $M_{c}$ and $R_{c}$ were obtained from (28). The MTI filters was designed with the LP algorithm (31). The frequency responses of the resulting LP filters are showed in Fig. 10 (a) and (b), red color, where $\mathrm{N}_{\mathrm{p}}=5$ and $\mathrm{N}_{\mathrm{p}}=10$, respectively. We can observe that the LP frequency responses are almost the same as those from the first two algorithms except that the levels are several $\mathrm{dB}$ higher. This resulted from that the LP filter coefficients could not be normalized. The IFs from the LP algorithms with stagger and uniform periods were listed in Table I. We can find that the IFs of the LP algorithm are 0.6 to $2.5 \mathrm{~dB}$ lower than the IFs of the eigenvalue algorithm.

For verifying exclusive effect of the staggered MTI filters, Fig. 11 (a) and (b) show frequency responses of the uniformperiod filters, where $\mathrm{N}_{\mathrm{p}}=5$ and $\mathrm{N}_{\mathrm{p}}=10$, respectively. They were designed with the same algorithms, and PRF is $360 \mathrm{~Hz}$; these spectral parameters of the interferences and target signal are the same as those in Fig. 10 (a) and (b). From the figures, we can observe that the responses of the MTI filters with uniform-period have wide and deep notches at intervals of $360 \mathrm{~Hz}$; these Nyquist notches can cause the targets of relative speed around $18 \mathrm{~m} / \mathrm{s}$ and its multiples, to be rejected. However, the staggered MTI filter can still detect these targets in a great detection probability.

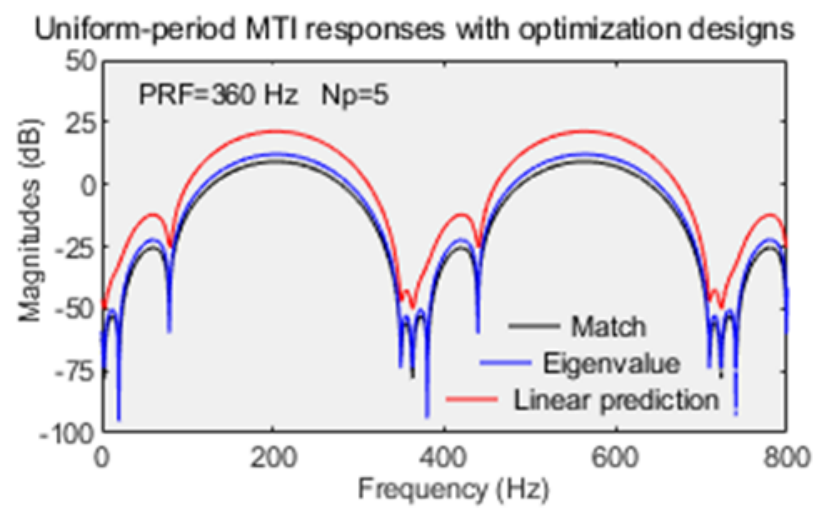

(a) $\mathrm{N}_{\mathrm{p}}=5$

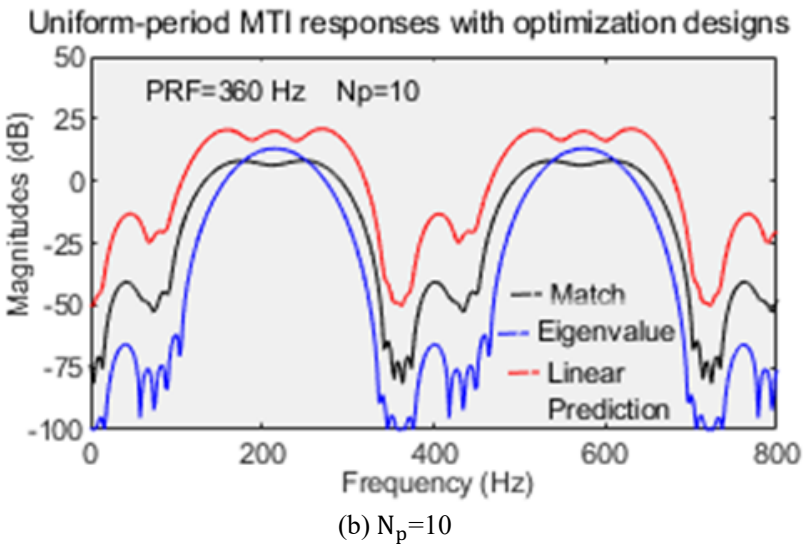

Fig.11 Uniform-period MTI frequency responses with three optimization algorithms

The eigenvalue, match and LP algorithms are optimized under the different applied conditions; thus, equations of their solutions are also different. The first two algorithms are suitable to design the MTI filters with a priori knowledge of radar environmental returns; the last LP algorithm is suitable to achieve an adaptive MTI filter, which takes less calculation load, and can transit to a stagger-period lattice filter.

\section{SEARCH FOR THE BEST PERIOD CODE}

From Fig. 10 to Fig. 11, we concluded that the staggerperiod MTI filters really solved the blind speed problem; 
from Table I, we also observed that the stagger-period filters had the optimized IFs. From the figures, however, we found that the frequency responses of the staggered filters are fluctuant in a certain degree. More measurements showed us that different period codes resulted in different fluctuations of the responses. Some references referred to this fluctuation minimization as a min-max design because their procedures were to adjust the MTI filter coefficients [14]. In fact, the fluctuation strongly depends on the period code. Thus, there exists the best period code to make the fluctuation least under certain conditions. For searching the best period code, the eigenvalue or match algorithm needs to be used to design the possible staggered filters, which all make the SCR maximized. Staggered covariance matrices of both the clutters plus noise and target signal are calculated by means of their a priori PSDs. After a batch of coherent pulses' samplings slides for a bank of filters, magnitudes of these filters' outputs are summed, then the resulting output forms a relatively flat response in the whole Doppler frequency region. The composite response is referred to as the velocity response of the staggered filters. Given a bank of staggered filters $h_{e}\left(t_{n}, t_{l}\right), l \in\left\{0,1, \cdots N_{p}-1\right\}, N_{p}$ filter length, and $n \in\{1$, $\left.2, \cdots \mathrm{N}_{\mathrm{w}}\right\}, \mathrm{N}_{\mathrm{w}}$ number of the bank filters, the velocity response of the bank filters can be calculated in terms of

$$
\mathrm{V}_{\mathrm{s}}(\mathrm{f})=\frac{1}{\mathrm{~N}_{\mathrm{w}}} \sum_{\mathrm{n}=1}^{\mathrm{N}_{\mathrm{w}}}\left|\mathrm{H}_{\mathrm{e}}\left(\mathrm{t}_{\mathrm{n}}, \mathrm{f}\right)\right| \quad 0 \leq \mathrm{f} \leq \mathrm{F}_{\mathrm{v}}
$$

where $F_{v}$ is blind frequency of the velocity response, and is equal to the extended frequency period $F_{p} ; H_{e}\left(t_{n}, f\right)$ is the frequency response of the nth filter, and ensures to maximize IF at $t_{n}$. In order to balance target detection in the region [0, $\left.F_{v}\right], V_{S}(f)$ is required to be a flat response as possible. Then, non-flatness of the velocity response is defined as the peak max minus valley min, i.e.,

$$
D_{v}=\max _{f}\left\{V_{s}(f)\right\}-\min _{f}\left\{V_{s}(f)\right\}
$$

where $f \in\left[0, F_{v}\right]$, excluding frequency region of the clutter notch. Different period code $\left\{\mathrm{k}_{1}: \mathrm{k}_{2}: \cdots \mathrm{k}_{\mathrm{N}_{\mathrm{t}}}\right\}, \mathrm{N}_{\mathrm{t}}$ code length, results in different $\left\{H_{e}\left(t_{n}, f\right)\right\}$ and different $D_{v}$. The less the $\mathrm{D}_{\mathrm{v}}$, the flatter the velocity response. The best period code can be searched by the following discrete nonlinear mathematical programming,

$$
\left\{\begin{array}{l}
\min _{\mathrm{D}_{\mathrm{v}}}\left(\mathrm{k}_{1}: \mathrm{k}_{2}: \cdots \mathrm{k}_{\mathrm{N}_{\mathrm{t}}}\right) \\
\mathrm{k}_{1}, \mathrm{k}_{2}, \cdots \mathrm{k}_{\mathrm{N}_{\mathrm{t}}} \text { are mutually prime } \\
\max _{\mathrm{i}}\left\{\mathrm{k}_{\mathrm{i}}\right\} / \min _{\mathrm{j}}\left\{\mathrm{k}_{\mathrm{j}}\right\} \leq \mathrm{R}_{\mathrm{t}} \\
\frac{1}{\mathrm{~N}_{\mathrm{t}}} \sum_{\mathrm{i}=1}^{\mathrm{N}_{\mathrm{t}}} \mathrm{k}_{\mathrm{i}} \geq \mathrm{R}_{\mathrm{f}}
\end{array}\right.
$$

where $\mathrm{R}_{\mathrm{t}}$ is a given stagger ratio, $\frac{1}{\mathrm{~N}_{\mathrm{t}}} \sum_{\mathrm{i}=1}^{\mathrm{N}_{\mathrm{t}}} \mathrm{k}_{\mathrm{i}}$ is extension factor of frequency period, and $R_{f}$ is a given value. The two parameters generally relate to pulse-transmitted technology.

As an example, we required $\mathrm{R}_{\mathrm{t}}=1.2$ and $\mathrm{R}_{\mathrm{f}}=26$; the available code numbers are sets of five integers from 25,26 , $27,28,29$, and 30 , and must include 25 and 30 for their stagger ratio 1.2. It was verified that the integers are mutually prime, and the frequency period extension is 27.6 or 27.4. Then, the last two conditions of (34) are met. Number of all the sets is $\mathrm{C}_{4}^{3} \mathrm{P}_{5}^{5}=480$, where $\mathrm{C}$ denotes combination, and $\mathrm{P}$ denotes permutation. When a few heuristic strategies are incorporated, the mathematical programming is efficiently solved. (1) Since five selected integers with shifting arrangements result in the same velocity response, e.g., code
25:26:27:29:30 and code 26:27:29:30:25, we only selected one of the five arrangements. (2) Since five selected integers with symmetric arrangements result in the same velocity response, e.g., code 25:26:27:29:30 and code 30:29:27:26:25, we only selected one of the two arrangements. (3) Search in the entire region $\left[0, \mathrm{~F}_{\mathrm{v}}\right]$ is not necessary because the peak max and valley min appear only within the region of double average PRFs in our experiments. After the three strategies were used, the calculation load was reduced to one in a hundred twenty. We selected only terrain clutter situation, which had a common Gaussian spectrum model, and its spectral parameters were selected as: power $=55 \mathrm{~dB}$, center $=0$ $\mathrm{Hz}$, standard variance $=7.2 \mathrm{~Hz}$; average PRF was $360 \mathrm{~Hz}$. The eigenvalue algorithm was used to design all the 48 filters. The best and worst period codes were both searched out in terms of (34).

Fig. 12 (a) shows the velocity responses of the MTI filters of two banks with the best code, 25:28:29:26:30, black color, and the worst period code, 25:26:28:30:27, blue color; the blind frequencies are 9.936 and $9.864 \mathrm{kHz}$, respectively. Fig. 12 (b) shows the same velocity responses except that the frequency axis was zoomed in for clear viewing. The two banks' filters are optimal to suppress the given terrain clutter, but the non-flatness of their velocity responses is much different: $\mathrm{D}_{\mathrm{v}}$ of the best code is $16.3 \mathrm{~dB}$, and $\mathrm{D}_{\mathrm{v}}$ of the worst code is $25.7 \mathrm{~dB}$. Additionally, the different filter design algorithms may result in different best period codes; however, their non-flatness values are quite close. See [10] for the search result from the match algorithm.

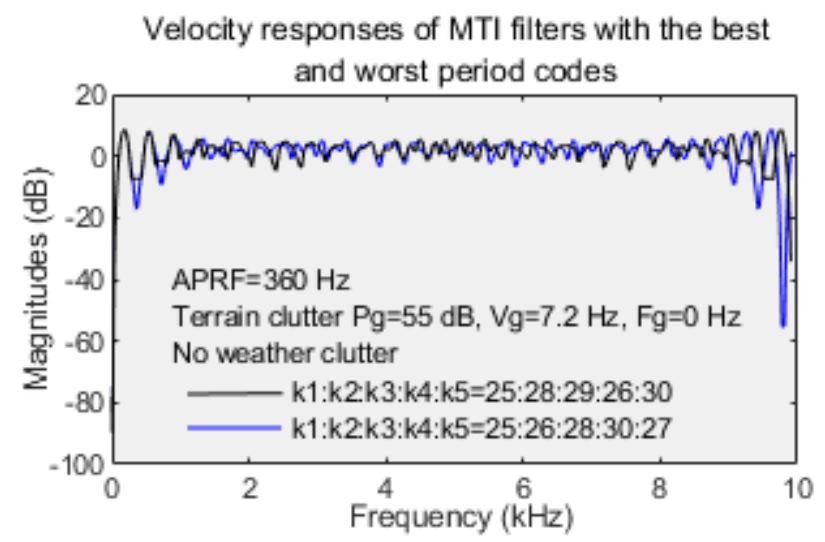

(a) frequency region of 0 to $10 \mathrm{kHz}$

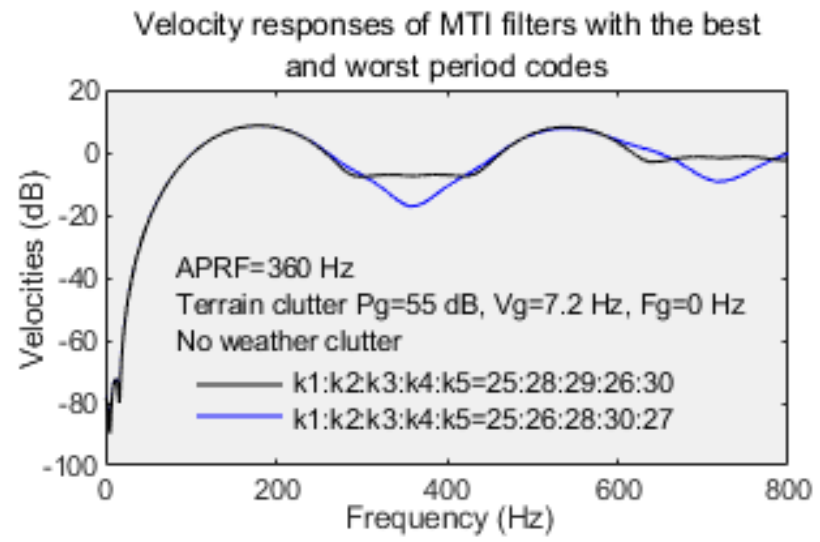

(b) frequency region of 0 to $800 \mathrm{~Hz}$

Fig. 12 Velocity responses of stagger-period MTI filters with the best and worst period codes 


\section{SUMMARIZATION}

Based on those theories of the uniform-period signal processing, the stagger-period signal processing has been developed, and a few theories and valuable applications were achieved. When the signal sampling frequency is not allowed to be high enough, we need to utilize the stagger-period technology to extend the high-pass frequency region. In this paper, we proposed the essential concepts and relevant definitions, studied the fundamental theories and design methods of the stagger-period FIR filters, and illustrated the experimental examples, graphs, and table. All the results are summarized as follows.

1) The stagger-period FIR filters are a sort of discrete-time FIR filters, and the uniform-period FIR filter is a special case of the stagger-period filters. The circular staggerperiod filters are a common type in practical designs. The exclusive characteristic of the stagger-period FIR filter is linear-time-variant. To get the desired frequency response, the successive filter impulse responses must vary at each input time. We proposed and proved the Fourier transform pair between the frequency and impulse responses of a stagger-period FIR filter, in a similar way to the Fourier transform pair of a uniform-period FIR filter.

2) Some exclusive concepts of the stagger-period FIR filters appear, such as average sampling period, frequency period extension, etc. The major property of the staggerperiod FIR filter is extension of the frequency period or Nyquist interval, which results from the uniform-period filter. This expands new application areas of the FIR filters, where the staggered filter not only forms a desired notch to reject interferences, but also close up the other undesired notches at Nyquist intervals to protect the signals appearing there, rather than that uniform-period FIR filters do.

3) Designs of the stagger-period FIR filter are not difficult but a little complicated. The conventional design of frequency-selective FIR filter with stagger periods needs to accomplish the inverse Fourier transform of the given passband plus stopband response, usually resulting in a Sinc impulse sequence. Then, we need to ensure the impulse periods to match the input signal periods, and to truncate the Sinc sequence to a desired length. Windowing the truncated impulse response is an effective approach to eliminate Gibbs' vibration, and the staggered window function is also time-variant. Alternatively, use of the match algorithm can also achieve an optimization design of the frequency-selective filters, which needs the given rectangle spectral model of interference and target signal, then accomplishes the solution of the algorithm to maximize SCR of the high-pass filter output.

4) As applications, we introduced three stagger-period algorithms to design the optimized MTI filter. Their criteria are the IF maximum while conquering the blind speed problem caused by uniform-period MTI filters. Theoretically, the eigenvalue, match, and LP algorithms all apply to inputs of stationary stochastic interferences, but they apply to inputs of stationary stochastic, deterministic, and no target signals, respectively. The three algorithms are optimized under the different applied conditions; thus, equations of their solutions are different.
According to our experimental data, IFs of the eigenvalue $\geq$ IFs of the match $\geq$ IFs of the LP; and all the IFs were between 55 and $49.5 \mathrm{~dB}$, so the three algorithms can effectively be applied to different situations, respectively.

5) To balance the detection probability of the flying targets within a whole velocity range, we proposed a mathematical programming to search the best period code, which was an acceptable approach to flatten the staggered frequency response. The programming criterion is peak-valley max minimization of the velocity response of an MTI filter bank. We illustrated an example, which required blind speed extension $\geq 26$ and stagger $P R F$ ratio $\leq 1.2$. The search results showed that the best period code resulted in the non-flatness $9.6 \mathrm{~dB}$ better than the worst code did.

\section{ACKNOWLEDGMENT}

This author is grateful to Professor Zheng Bao in Xi'an Electronic Science and Technology University, in China, for his approval and great advices during research of the project.

\section{REFERENCES}

[1] John G. Proakis and Dimitris G. Manolakis, Digital Signal Processingprinciples, algorithms, and applications, 1st ed. USA, New Jersey: Prentice-Hall Inc., 1996, ch.4.

[2] Alan V. Oppenheim, Ronald W. Schafer, and John R. Buck, DiscreteTime Signal Processing, 2nd ed. USA, New Jersey: Prentice-Hall Inc., 1999, pp. 69, 327-345.

[3] N. K. Bose, Digital Filters-Theory and Applications; 1st ed. New York: Elsevier Science Publishing Co. Inc., 1985, ch.4.

[4] J. K. Hsiao, "On the optimization of MTI clutter rejection," IEEE Trans. on AES, vol.10, pp. 570-578, Sept. 1974.

[5] G. A. Andrews, "Optimization of radar Doppler filters to maximize moving target detection," NAECN'74, Record, pp. 279-283. Washington D.C. May 1974.

[6] Bassem R. Mahafza, Radar Systems Analysis and Design Using MatLab, 1st ed. New York: Chapman \& Hall/CRC, 2000, ch.9.

[7] Mehmet Ispir and Cagatay Candan, "On the design of staggered moving target indicator filters," IET Radar, Sonar \& Navigation, vol.10, iss.1, pp. 205-215, Jan. 2016.

[8] John Y. N. Cho and Mark E. Weber, "Terminal Doppler weather radar enhancements," IEEE National Conference on Radar, pp. 1245-1249, Washington DC, May 2010.

[9] Andrzej Wojtkiewicz and Michal Tuszynski, "Application of Dirichlet transform in analysis of nonuniformly sampling signals," Proc. ICASSP, pp. v25-v28, San Francisco, 1992.

[10] Xubao Zhang, "Fourier analyses of stagger-period sequences," IJRDOJournal of Electrical and Electronics Engineering, vol.3, iss.9, pp. 112, Sept. 2017.

[11] D. DeLong and E. Hofstetter, "On the design of optimum radar waveforms for clutter rejection," IEEE Trans on Inf. Theory, vol.13, iss.3, pp. 454-463, Mar. 1967.

[12] Athanasios Papoulis, Probability, Random Variables, and Stochastic Processes, 4th ed., USA, Boston: McGraw-Hill, Inc. 2002, pp. 264, 478, 483, 587.

[13] John Makhoul, "Linear prediction: a tutorial review," Proceedings of the IEEE, vol. 63, no. 4, pp. 561-580, Apr. 1975.

[14] M. Steiner, "A minimax approach to the design of Doppler filters," IEEE Trans. on AES, vol. 27, iss.3, pp. 481-486, May 1991.

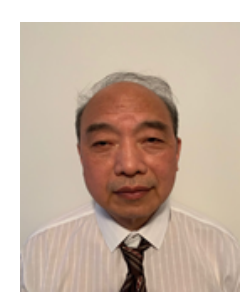

Xubao Zhang received his doctorate in Electronics from Xi'an Electronic Science and Technology University in China in Dec. 1989 and was a Postdoctoral Fellow at McMaster University in Canada in 1993. He has been interested in radar signal processing study and hearing aid technology research.

He worked as Associate Professor at electronic engineering department of Xi'an Electronic Science and Technology University, and worked as an Electronic engineer at Linyun Radio, when he was in China. And he worked 
as an Electroacoustic and EMC engineer with Unitron Hearing, also with Oticon Canada and Beltone Canada after he came to Canada.

$\mathrm{He}$ is the author of one book and more than 40 articles. He received an award: The Second-Prize of Science and Technology Progress, granted by The National Science and Technology Committee of China. July 1992 